\title{
Disponibilidade hídrica superficial da bacia hidrográfica do rio Suaçuí: análise por diferentes metodologias de definição de vazão de referência
}

\author{
Surface water availability of the Suaçuí river basin: analysis by different methodologies for \\ defining the reference flow rate \\ Disponibilidad de agua superficial en la cuenca del río Suaçuí: análisis mediante diferentes \\ metodologías para definir el caudal de referencia
}

Recebido: 20/01/2022 | Revisado: 27/01/2022 | Aceito: 04/02/2022 | Publicado: 07/02/2022

\author{
Guilherme de Barros Moreira \\ ORCID: https://orcid.org/0000-0002-1271-7434 \\ Universidade Federal de Itajubá, Brasil \\ E-mail: guilherme.marlieria@gmail.com \\ James Lacerda Maia \\ ORCID: https://orcid.org/0000-0001-8792-8722 \\ Universidade Federal de Itajubá, Brasil \\ E-mail: jamesmaia@unifei.edu.br \\ João Paulo Oliveira Silva \\ ORCID: https://orcid.org/0000-0002-2541-7289 \\ Universidade Federal de Itajubá, Brasil \\ E-mail: jpoliveirasilva@unifei.edu.br
}

\begin{abstract}
Resumo
Para análise de disponibilidade hídrica de uma bacia hidrográfica o conhecimento da vazão de referência torna-se indispensável. No estado de Minas Gerais utiliza-se a vazão $\mathrm{Q}_{7,10}$, em que é outorgada uma parcela dessa vazão referencial, esta que pode ser definida por diferentes metodologias. Nesse estudo, objetivou-se comparar diferentes metodologias de definição de vazão de referência para análise da disponibilidade hídrica superficial da bacia hidrográfica do rio Suaçuí (Minas Gerais), sendo elas: análise estatística de séries históricas de vazões nas estações fluviométricas; Deflúvios superficiais no estado de Minas Gerais; e Estudo de regionalização de vazão para o aprimoramento do processo de outorga no estado de Minas Gerais. Verificou-se consideráveis variações entre os métodos utilizados, com intervalos de $-19,94 \%$ a 1.304,6\% comparando os dois métodos de regionalização de vazões utilizados, em relação à análise dos dados existentes. Pelos diferentes métodos, verificou-se que as vazões captadas nas respectivas sub-bacias não produzem impactos capazes de comprometer a disponibilidade hídrica, exceto para a área à montante da estação Fazenda Corrente, em que os resultados indicam certo grau de comprometimento da disponibilidade hídrica. Recomenda-se pesquisas futuras que comparem outros métodos de regionalização de vazões, buscando resultados com menores variações estatísticas em relação às estações fluviométricas observadas, ou até mesmo o desenvolvimento de métodos específicos à bacia hidrográfica estudada, no sentido de contribuir para o processo de tomada de decisão no gerenciamento dos recursos hídricos.
\end{abstract}

Palavras-chave: Outorga; Regionalização de vazões; Séries históricas.

\begin{abstract}
For the analysis of water availability in a hydrographic basin the knowledge of the reference flow rate becomes indispensable. In the state of Minas Gerais the flow rate $\mathrm{Q}_{7,10}$, is used, in which a portion of this reference flow rate is granted, which can be defined by different methodologies. In this sense, this study aims to analyze the surface water availability of the Suaçuí river basin (MG) using three methodologies to define the reference flow rate: statistical analysis of historical flow series in the fluviometric stations; Surface water runoff in the state of Minas Gerais; and Flow regionalization study to improve the allocation process in the state of Minas Gerais. Considerable variations between the methods used were verified, with intervals of $-19.94 \%$ to $1304.6 \%$ comparing the two flow regionalization methods used, in relation to the analysis of the data from the fluviometric stations. By the different methods, the water levels captured in the respective sub-basins do not produce impacts capable of compromising water availability, except for the area upstream of the "Fazenda Corrente" station, where the results indicate a certain degree of compromising water availability. Future research that compares other methods of flow regionalization is recommended, seeking results with smaller statistical variations in relation to the observed fluviometric stations, or even the development of specific methods for the studied watershed, in order to contribute to the decision-making process in the management of water resources.
\end{abstract}

Keywords: Concession; Historical series; Streamflow regionalization. 


\begin{abstract}
Resumen
Para analizar la disponibilidad de agua de una cuenca hidrográfica el conocimiento del caudal de referencia se hace indispensable. En el estado de Minas Gerais, se utiliza el caudal $\mathrm{Q}_{7,10}$, en el que se concede una parte de este caudal de referencia, que puede definirse por diferentes metodologías. En este sentido, este estudio tiene como objetivo analizar la disponibilidad de agua superficial de la cuenca del río Suaçuí (MG) utilizando tres metodologías para definir el caudal de referencia: análisis estadístico de las series de caudales históricos en las estaciones fluviométricas; escorrentía superficial en el estado de MG; y estudio de regionalización de caudales para la mejora del proceso de asignación en el estado MG. Las variaciones entre los métodos utilizados son considerables, con intervalos de 19,94\% a 1.304,6\%, comparando los dos métodos de regionalización del flujo utilizados, en relación con el análisis de los datos de las estaciones fluviométricas. Por los diferentes métodos, los caudales captados en las respectivas subcuencas no producen impactos capaces de comprometer la disponibilidad de agua, excepto en la zona aguas arriba de la estación "Fazenda Corrente", donde los resultados indican un cierto grado de compromiso de la disponibilidad de agua. Se recomienda la realización de futuras investigaciones que comparen otros métodos de regionalización de caudales, buscando resultados con menores variaciones estadísticas en relación a las estaciones fluviométricas, o incluso el desarrollo de métodos específicos para la cuenca hidrográfica estudiada, con el fin de contribuir al proceso de toma de decisiones en la gestión de agua.
\end{abstract}

Palabras clave: Concesión; Regionalización de caudales; Series históricas.

\title{
1. Introdução
}

Para a existência de vida, a água é um elemento natural indispensável, e por isso, o reconhecimento do seu valor econômico e a preocupação com a preservação deste bem mineral deve ser primordial.

Para Tundisi (2003), a água deve ser objeto de políticas sistêmicas a fim de garantir a sustentabilidade das futuras gerações, e por ser o recurso natural de maior relevância, pois está presente e dinamiza todos os ciclos ecológicos, sendo parte essencial dos ciclos biogeoquímicos e da biodiversidade.

É notável a relação existente entre a água e o desenvolvimento de uma região. Os primeiros países a avançarem no desenvolvimento econômico, os chamados países de primeiro mundo, alcançaram tal nível utilizando-se de água, passando a valorizar este recurso e abordar as questões de gestão e gerenciamento deste bem (Borsoi \& Torres, 1997).

Segundo Medeiros (2000), a necessidade de água por parte do homem acompanhou o crescimento populacional, mas o aumento da escala de consumo de água pela sociedade humana se deve principalmente ao intenso processo de industrialização e de diversificação das atividades econômicas, e a migração da população do campo para as cidades.

A Lei Federal n 9.433/1997 (Brasil, 1997) institui no país a Política Nacional de Recursos Hídricos. A Lei trouxe seis instrumentos para a gestão dos recursos hídricos, dentre os quais, está a outorga de direitos de uso de recursos hídricos, que tem como objetivo assegurar o controle quantitativo e qualitativo dos usos da água e o efetivo exercício dos direitos de acesso à água.

Segundo esta Lei, no Art. $7^{\circ}$, a outorga deve estar vinculada a estudos referentes ao "balanço entre disponibilidades e demandas futuras dos recursos hídricos, em quantidade e qualidade, com identificação de conflitos potenciais”. Nesse sentido, a disponibilidade hídrica é a informação essencial que fundamenta a análise e decisão sobre a outorga.

A identificação da relação entre as demandas, as atividades associadas aos usos em uma bacia e a disponibilidade de água para supri-las são fundamentais para o estabelecimento de um bom diagnóstico de recursos hídricos que fornecerá suporte à gestão das águas. A dinâmica econômica regional acompanha as tendências de disponibilidade e qualidade das águas ao longo do tempo. $\mathrm{O}$ crescimento de atividades poluidoras sem o controle adequado, por exemplo, pode provocar degradação da qualidade das águas, ou inversamente, a diminuição das mesmas refletirá em melhorias (ANA, 2017).

De acordo com Souza (2011), a disponibilidade hídrica de um curso d'água pode ser conhecida a partir da obtenção de dados de monitoramento de estações fluviométricas, no entanto, esses dados são raros, devido à dificuldade em cobrir toda a rede hidrográfica. A falta de dados fluviométricos, o alto custo de implantação, operação e manutenção de uma rede hidrométrica em toda a rede hidrográfica das bacias e/ou a ausência de dados espaço-temporais são obstáculos para a 
existência de dados precisos referentes ao quantitativo hídrico das redes de drenagem. Diante desse cenário, resultados obtidos em determinado sistema hídrico são correlacionados para trechos não monitorados, através de métodos específicos.

Para análises de disponibilidade hídrica de uma bacia hidrográfica, o conhecimento da vazão de referência torna-se indispensável. Ribeiro (2000) explica que vazão de referência é o estabelecimento de um valor de vazão que determina o limite para utilização da água em um curso d'água. Harris et al. (2000) afirmam que o critério de vazão de referência para utilização das águas é um procedimento válido para a proteção dos rios, pois as alocações de água para os usos pretendidos são geralmente feitas a partir de uma vazão de base de pequeno risco.

De acordo com Silva e Monteiro (2004), as vazões de referência utilizadas como outorgáveis são as vazões mínimas, como forma de condicionar uma alta garantia de água no manancial. A partir dessa condição, são realizados os cálculos de alocação da água, de modo que, quando essas vazões mínimas ocorrerem, os usuários ou os usos prioritários mantenham, de certa forma, suas retiradas de água. Dessa forma, quando o poder público analisa uma solicitação de outorga de um dado usuário, considerando uma captação a fio d'água em cursos d'água superficiais, ele deve considerar a vazão solicitada para o empreendimento, frente ao percentual definido como outorgável, em relação à vazão de referência adotada.

Existem várias metodologias para definição da vazão de referência, mas em geral são vazões de elevada permanência no tempo, calculadas de forma estatística, podendo citar como as mais comuns: $\mathrm{Q}_{90}$, $\mathrm{Q}_{95} \mathrm{e} \mathrm{Q}_{7,10}$.

A Q $Q_{90}$ é a vazão determinada a partir das observações em um posto fluviométrico em certo período de tempo, em que em $90 \%$ daquele período as vazões foram iguais ou superiores a ela. Em outras palavras, pode-se aceitar que existe um nível de 90\% de garantia de que naquela seção do curso d'água as vazões sejam maiores do que o Q90 (Matias, 2018).

A $Q_{95}$ tem o significado semelhante que a $Q_{90}$, entretanto, a garantia corresponde a $95 \%$ do tempo de observação. Isso significa que a vazão em determinado corpo d'água é igual ou superior àquele valor em 95\% do tempo (Matias, 2018).

Já a $\mathrm{Q}_{7,10}$ é a menor vazão média consecutiva de sete dias que ocorreria em um período de retorno de 10 anos (Matias, 2018). O cálculo da $\mathrm{Q}_{7,10}$ é probabilístico, enquanto os da $\mathrm{Q}_{90}$ e da $\mathrm{Q}_{95}$ decorrem de uma análise de frequências.

Segundo Medeiros (2000), a vazão de referência utilizada é a simulada para uma situação crítica de estiagem, como é o caso da $Q_{90}, Q_{95}$ e $Q_{7,10}$. Assim, é outorgada uma parcela da vazão referencial (variável entre as unidades federadas), supondo-se que o restante seja mantido no leito do rio para a proteção do ecossistema (vazão ecológica).

No Brasil, cada Estado tem adotado critérios particulares para o estabelecimento das vazões máximas outorgáveis, sem, porém, apresentar na legislação, justificativas técnicas para adoção desses valores. O Quadro 1 apresenta alguns exemplos. 
Quadro 1 - Exemplo de vazões de referência e critérios para vazões máximas outorgáveis adotadas em alguns Estados brasileiros.

\begin{tabular}{|c|c|c|c|}
\hline Estado & Regulamentação & Vazão de Referência & Critérios \\
\hline Minas Gerais & $\begin{array}{c}\text { Resolução Conjunta } \\
\text { SEMAD/IGAM n } \\
1548 / 2012\end{array}$ & $\mathrm{Q}_{7,10}$ & $\begin{array}{c}\text { Vazão máxima outorgável de 50\% da } \\
\mathrm{Q}_{7,10} \text {. Exceções em algumas bacias } \\
\text { que a vazão máxima outorgável é de } \\
30 \% \text { da }\end{array}$ \\
\hline Mato Grosso \\
\hline Rio de Janeiro & $\begin{array}{c}\text { Resolução } \\
\text { CEHIDRO 27/09 }\end{array}$ & $\mathrm{Q}_{95}$ & $\begin{array}{c}\text { Vazão máxima outorgável = 70\% da } \\
\text { Q95 }\end{array}$ \\
\hline Espírito Santo & $\begin{array}{c}\text { Instrução } \\
\text { Normativa } \mathrm{n}^{\mathbf{0}} \\
013 / 2009\end{array}$ & $\mathrm{Q}_{7,10}$ & $\begin{array}{c}\text { Vazão máxima outorgável de 50\% da } \\
\text { Q7,10 }\end{array}$ \\
\hline
\end{tabular}

Fonte: Elaboração dos autores (2021).

É importante ressaltar que as vazões de referência $\mathrm{Q}_{7,10}$, $\mathrm{Q}_{90} \mathrm{e} \mathrm{Q}_{95}$ são calculadas com base na análise dos períodos críticos de estiagem, tem restringido um maior uso de água em meses fora do período de estiagem (Medeiros, 2000). Este fato, inclusive, tem sido objeto de vários estudos sobre a sazonalidade no estabelecimento de vazões de outorga. Maia, Mauad e Barbosa (2005), por exemplo, objetivaram subsidiar o Comitê de Bacia Hidrográfica do Rio Sapucaí indicando vazões de outorga de direito de uso das águas para esta bacia. A vazão a ser outorgada foi estabelecida, sempre, em $30 \%$ da vazão de referência $\mathrm{Q}_{7,10}$, para períodos de estiagem, e um valor acima deste para períodos úmidos, aplicando um fator de correção de sazonalidade mensal.

Além disso, segundo Stinghen e Mannich (2019), há uma busca sólida de novas ferramentas e modelos a serem incorporados às análises técnicas que tragam facilidade e maior confiabilidade na determinação de valores para as vazões de referência que são a base para a definição das disponibilidades hídricas.

Neste contexto, Garbossa e Pinheiro (2015) avaliaram, para as bacias de pequeno porte situadas no entorno da Ilha de Santa Catarina, os desvios entre a estimativa das vazões de referência, a partir de medições pontuais de vazão e do estudo de regionalização de vazões. Os resultados apontaram que a taxa de urbanização da bacia contribui significativamente para a incerteza na estimativa da vazão de referência. Os autores concluíram que a real minimização de incertezas e erros pode ser conseguida com o monitoramento fluviométrico contínuo de pequenas bacias hidrográficas ou a adoção de metodologias de estimativas apropriadas para estas bacias.

Para avaliação da disponibilidade hídrica de um curso d'água, pode-se citar como exemplo o método de regionalização hidrológica (ou de vazões), que consiste em um conjunto de ferramentas que exploram ao máximo as informações fluviométricas e pluviométricas existentes, visando a estimativa das variáveis, funções ou parâmetros hidrológicos em regiões com dados limitados (Tucci, 2000).

Segundo Pereira (2012), a regionalização hidrológica consiste, basicamente, na definição de regiões hidrologicamente homogêneas, onde a variável regionalizada possui tendências hidrológicas semelhantes, ou seja, há o agrupamento espacial de distribuições estatísticas similares.

Euclydes et al. (2001) afirmam que o processo de regionalização da vazão mínima apesar de ser exaustivo, é considerado simples, pois depende apenas da disponibilidade de dados e de ferramentas computacionais adequadas, além de recursos humanos qualificados. 
A regionalização de vazões é bastante utilizada na obtenção da disponibilidade hídrica para concessão de outorga, permitindo maior agilidade e automação dos procedimentos. No Estado de Minas Gerais, o órgão ambiental responsável (Instituto Mineiro de Gestão das Águas - Igam), recomenda como referência bibliográfica, no seu "Manual Técnico e Administrativo de Outorga de Direito de Uso de Recursos Hídricos no Estado de Minas Gerais" (Igam, 2010), para determinação das vazões de referência em um processo de outorga, na falta de dados das séries históricas de vazões, o trabalho desenvolvido por Souza (1993) para a Companhia de Saneamento de Minas Gerais.

No estudo de Souza (1993) tem-se mapas contendo isolinhas de rendimento específico, em L/s.km², para vazões mínimas e máximas - com 10 anos de período de retorno, e média de longo termo para todo o Estado. As vazões de referência $\mathrm{Q}_{7,10}$ em cada seção dos cursos de água são obtidas através de metodologia que associa o rendimento específico de cada região à área de drenagem em análise e às características físicas, de solo e meteorológicas das bacias hidrográficas.

Vale ressaltar que os estudos de regionalização desenvolvidos geralmente utilizam as vazões existentes, quando estas informações são representativas; no entanto, quando os dados são deficientes, a regionalização fica comprometida (Obregon et al.,1999).

O método da regionalização de vazões, no qual dados pontuais são espacializados, tendo-se por base características físicas ou geomorfológicas homogêneas (Tucci, 2000), podem resultar em erros importantes em bacias de pequeno porte sem histórico de monitoramento (Soares et al., 2010). Hrachowitz et al. (2013) destacam a importância do aprimoramento na compreensão dos processos envolvidos, permitindo o desenvolvimento de técnicas sofisticadas de regionalização de vazão em bacias não monitoradas.

Nesse sentido, segundo estudo publicado por Igam (2012, p.13), intitulado "Estudo de Regionalização de Vazão para o Aprimoramento do Processo de Outorga no Estado de Minas Gerais":

O preceito estatístico de que o uso das equações de regressão deve ficar restrito apenas à faixa de variação da variável independente utilizada, somada ao fato de que as estações fluviométricas são instaladas em seções para as quais já existe uma grande área de contribuição, acaba por restringir a utilização das equações de regionalização a uma parcela muito reduzida da hidrografia, uma vez que a maior parte da hidrografia apresenta áreas de drenagem inferiores à área de contribuição relativa às estações onde são medidas as vazões. Existe, entretanto, a tendência de utilização da regionalização de forma generalizada, sem um questionamento maior da qualidade de seus resultados, o que pode comprometer o processo de tomada de decisão no gerenciamento dos recursos hídricos, gerando problemas de gestão e conflitos.

Baseado nestes fatos, o método de regionalização de vazões desenvolvido por Igam (2012) buscou alternativas para reduzir os efeitos destes fatores. A utilização de uma variável caracterizada como precipitação menos a inércia hídrica está fundamentada no fato de que boa parte da precipitação que ocorre em uma bacia hidrográfica é transformada em evapotranspiração, não sendo, portanto, convertida em escoamento na hidrografia. Desta forma, apenas uma parte da precipitação vai constituir contribuição efetiva para a formação das vazões mínimas e média. A utilização desta variável oportunizou, em muitas bacias hidrográficas a obtenção de melhores ajustes para as equações de regionalização e, consequentemente, uma melhor representatividade para a estimativa das vazões.

Buscando reduzir os riscos associados à extrapolação das vazões para as regiões fora da amplitude de variação das variáveis independentes, foi proposta a uma imposição de restrição, de modo que as vazões extrapoladas nestas regiões não ultrapassem um limite físico conhecido. No caso das vazões médias de longa duração, o limite físico estabelecido foi o maior coeficiente de escoamento correspondente às estações fluviométricas utilizadas no estudo e, no caso das vazões mínimas, o limite de imposição constituiu a máxima vazão específica estimada nas estações fluviométricas consideradas no estudo (Igam, 2012).

Considerando que os procedimentos adotados no estudo de Igam (2012) permitem minimizar o risco de 
superestimativa das vazões para as regiões onde é feita a extrapolação, possibilitando uma gestão mais segura dos recursos hídricos, este método de regionalização de vazões foi um dos escolhidos para realização das análises de disponibilidade hídricas neste trabalho.

De acordo com Pereira (2012), apesar das dificuldades e imprecisões inerentes à regionalização, trata-se de uma ferramenta útil na gestão dos recursos hídricos, visto que possibilita a determinação da disponibilidade hídrica da bacia hidrográfica ainda sem monitoramento, para posterior gerenciamento dos usos múltiplos da água por meio da outorga.

Parajka et al. (2005) compararam diferentes métodos de regionalização de parâmetros hidrológicos para bacias hidrográficas na Áustria, com área variando de 10 a $9.770 \mathrm{~km}^{2}$ e diversas condições de relevo, precipitação e uso do solo, obtendo bom desempenho no método baseado na definição de regiões homogêneas e na similaridade das características fisiográficas das bacias.

A cada ano cresce o número de demandas de fiscalização sobre conflitos pelo uso da água recebidas no órgão ambiental estadual de Minas Gerais (SEMAD, 2019). Consoante a isso, a identificação da relação entre as demandas, as atividades associadas aos usos em uma bacia e a disponibilidade de água para supri-las são fundamentais para o estabelecimento de um bom diagnóstico de recursos hídricos que fornecerá suporte à gestão da água.

Nesse sentido, objetivou-se com este estudo comparar diferentes metodologias de definição de vazão de referência para análise da disponibilidade hídrica superficial da bacia hidrográfica do rio Suaçuí (Minas Gerais).

\section{Metodologia}

\subsection{Caracterização da área de estudo}

A Unidade de Planejamento e Gestão dos Recursos Hídricos CH DO4 (Comitê de Bacia Hidrográfica do rio Suaçuí) é composta pelas bacias hidrográficas do rio Suaçuí Grande, que ocupa uma área de $12.413 \mathrm{~km}^{2}$, do rio Suaçuí Pequeno (área de $1.720 \mathrm{~km}^{2}$ ) e pela bacia do rio Corrente Grande, com área de $2.478 \mathrm{~km}^{2}$ (Figura 1).

Figura 1 - Principais sub-bacias hidrográficas e rios.

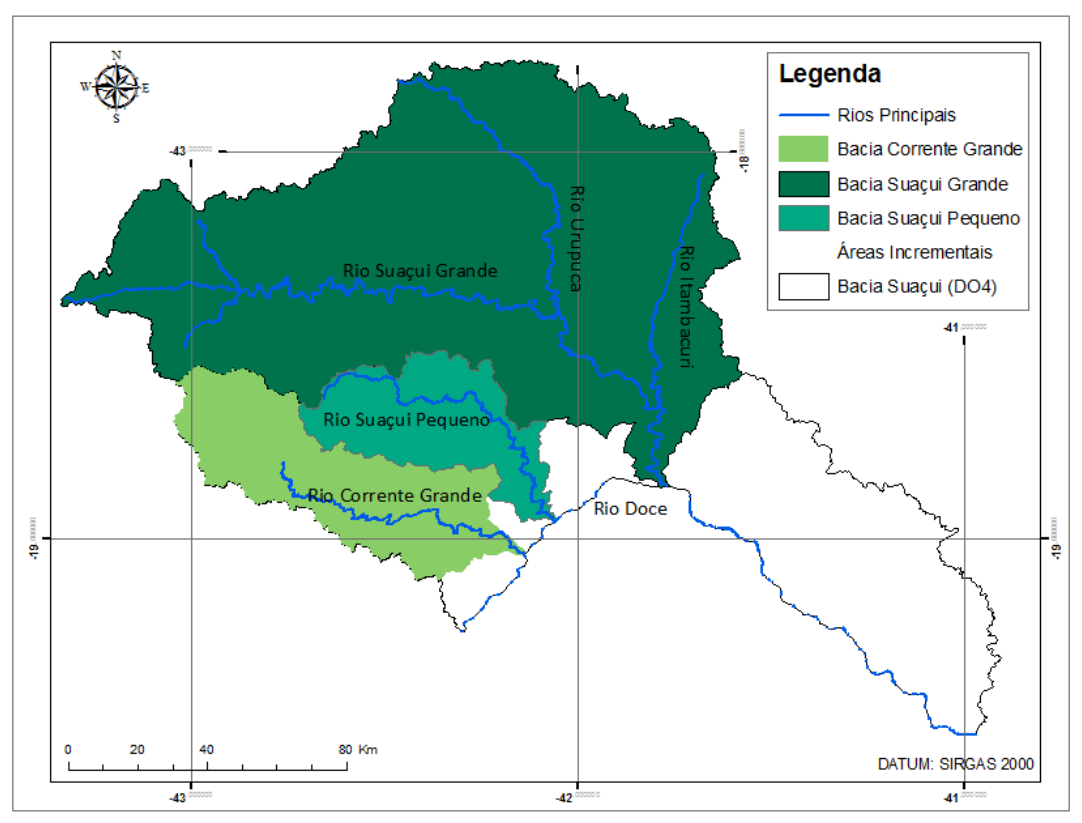

Fonte: Autores (2021). 
Além destas, a área da CH DO4 ainda é acrescida das áreas de drenagem de outros córregos de contribuição hídrica menos representativas, que drenam diretamente para o rio Doce pela sua margem esquerda, chamada área incremental Suaçuí (DO4), ocupando 4.945 km² (Consórcio ECOPLAN - LUME, 2010).

Os principais rios da CH DO4 são o Suaçuí Grande, Suaçuí Pequeno e Corrente Grande. Em menor expressão existe o Rio Itambacuri, além de outros pequenos córregos localizados nas chamadas áreas incrementais, os quais drenam diretamente para a calha do rio Doce (Consórcio ECOPLAN - LUME, 2010).

\subsection{Caracterização do estudo}

As pesquisas podem ser caracterizadas em diferentes aspectos, a partir dos métodos e procedimentos utilizados. O presente estudo é classificado quanto a abordagem em pesquisa quantitativa e, em relação aos métodos utilizados, como um estudo de caso.

Segundo Pereira et al. (2018), nos métodos quantitativos os dados obtidos podem ser analisados por meio ferramentas matemáticas, que envolvem estatísticas, métodos numéricos, equações matemáticas, entre outras. Uma vez que este estudo discorre sobre a disponibilidade hídrica superficial, utiliza-se a abordagem quantitativa para atingir os objetivos.

Por sua vez, os estudos de casos descrevem e analisam, de forma mais detalhada, algum acontecimento ou fenômeno com características particulares, de caráter exploratório e investigatório (Pereira et al., 2018). Tendo em vista que este trabalho avalia a bacia hidrográfica do rio Suaçuí Grande, com suas peculiaridades frente a outras unidades de gestão, pode-se classificar nessa categoria.

\subsection{Procedimentos metodológicos}

Neste trabalho, de forma a cumprir os objetivos propostos, aplicou-se a metodologia adaptada do manual "Metodologia para Elaboração do Zoneamento Ambiental Produtivo", em sua 33 edição SEMAD/SEAPA-MG (Faria et al., 2016), que consiste, basicamente, na análise da demanda versus disponibilidade hídrica da bacia hidrográfica estudada.

Os dados de outorgas foram consultados no banco de dados do Igam, órgão ambiental competente do Estado de Minas Gerais. Os mesmos foram coletados junto à Infraestrutura de Dados Espaciais do Sistema Estadual de Meio Ambiente e Recursos Hídricos - IDE-SISEMA, em 28 de dezembro de 2020.

Após a obtenção dos dados para outorgas válidas, em planilha Excel e outro arquivo em formato Shape, houve o processamento nos softwares Microsoft Excel e ArcGis 10.0. Foram aplicadas várias seleções por atributos, no intuito de filtrar os dados específicos e necessários no estudo. Considerou-se as captações superficiais de usos consuntivos, com outorga deferida, renovada ou retificada. Verificou-se também a ocorrência de processos repetidos.

No website da SEMAD (Secretaria de Estado de Meio Ambiente e Desenvolvimento Sustentável), verificou-se as portarias de outorga e as respectivas vazões de captação de cada processo, principalmente no que se refere à unidade de medida (L/s ou m³/s, esta que foi utilizada na posterior padronização).

Nesta pesquisa, foi considerada a vazão do mês setembro, uma vez que corresponde ao mês fim do ano hidrológico, que marca a transição entre os períodos seco e chuvoso. Além disso, no mês de setembro, todos os usuários realizavam a captação (alguns não captam no período chuvoso).

Para a análise da disponibilidade hídrica da $\mathrm{CH}$ DO4, foram utilizadas 3 metodologias para definição da vazão de referência $\mathrm{Q}_{7,10}$, para efeitos de comparação e a favor da segurança, uma vez que cada método possui suas deficiências, como as incertezas contidas nos métodos de regionalização de vazão. Portanto, os métodos utilizados foram os seguintes:

- Análise estatística a partir das séries históricas de vazões nas estações fluviométricas disponíveis na CH DO4;

- Deflúvios Superficiais no Estado de Minas Gerais (Souza, 1993); e 
- Estudo de Regionalização de Vazão para o Aprimoramento do Processo de Outorga no Estado de Minas Gerais (Igam, 2012).

Pode-se determinar a disponibilidade hídrica de um curso d'água por meio de dados de monitoramento de estações fluviométricas, porém, esses dados são raros, devido à dificuldade em cobrir toda a rede hidrográfica. Nesse contexto, foi necessário restringir a área de estudo de acordo com as estações fluviométricas existentes e com dados de vazão disponíveis no banco de dados do Portal Hidroweb, da Agência Nacional das Águas e Saneamento Básico (ANA). Por isso, as análises foram feitas considerando as seguintes áreas (Tabela 1).

Tabela 1 - Estações fluviométricas consideradas.

\begin{tabular}{ccc}
\hline Estação fluviométrica & Código & Dados de vazão \\
\hline Vila Matias Montante & 56891900 & 1965 a 2014 \\
São Pedro do Suaçuí & 56860000 & 1965 a 2014 \\
Campanário & 56851000 & 1938 a 2021 \\
Fazenda Corrente & 56845000 & 1952 a 2018 \\
\hline
\end{tabular}

Fonte: Autores (2021).

A Figura 2 apresenta a localização das estações fluviométricas.

Figura 2 - Áreas de estudo delimitadas de acordo com as estações fluviométricas disponíveis.

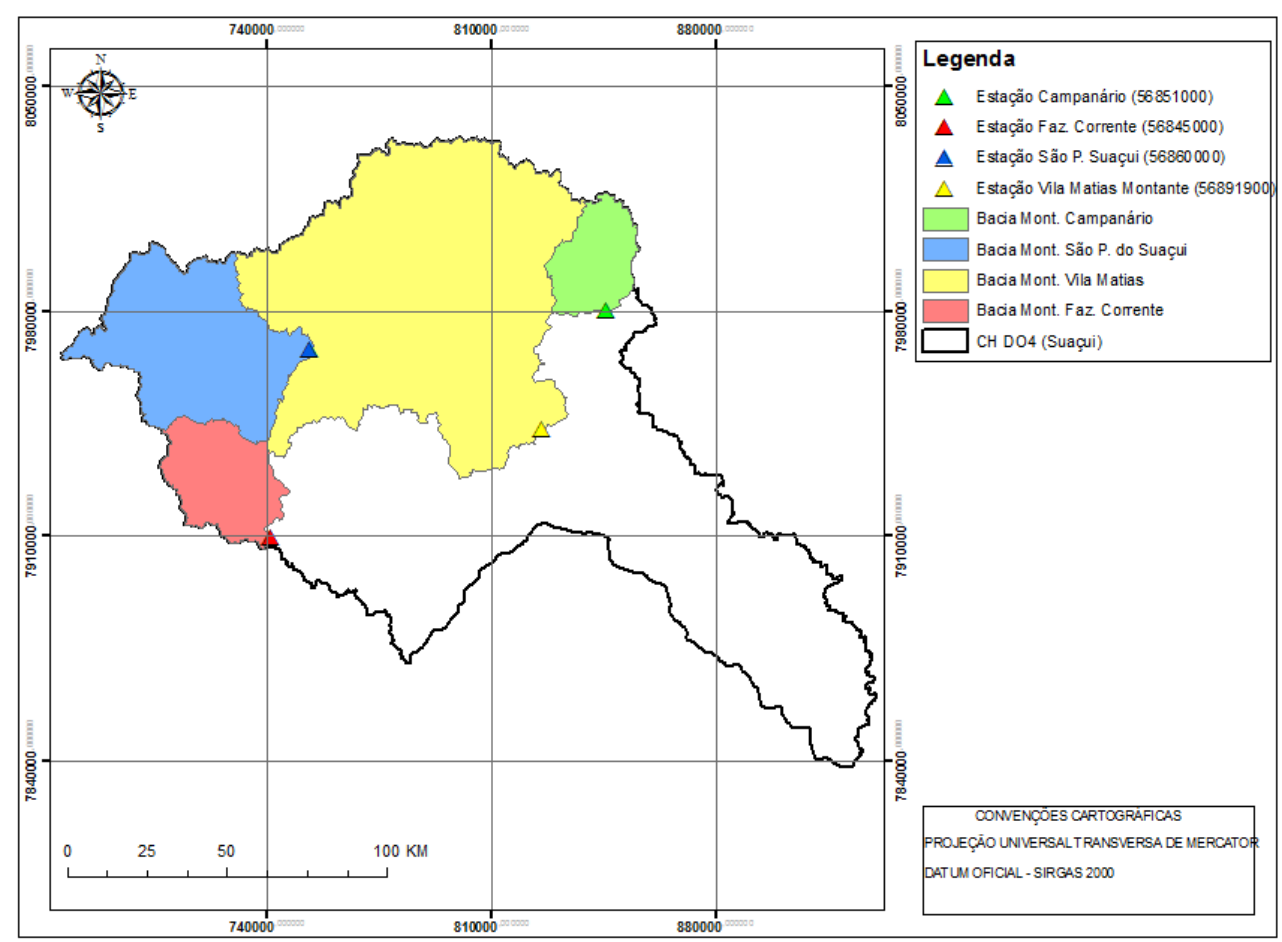

Fonte: Autores (2021).

A restrição foi necessária tendo em vista a necessidade das séries históricas de vazões da CH DO4, as quais só foram obtidas para as estações especificadas. Na bacia do rio Suaçuí Pequeno não foram encontradas estações fluviométricas com dados de medição de vazão, o que impossibilitou a análise das séries históricas de vazões do curso d'água em questão.

Os dados obtidos foram processados por meio do software SisCAH 1.0 - Sistema Computacional para Análises Hidrológicas, com objetivo de verificar os valores de $\mathrm{Q}_{7,10}$ para cada estação fluviométrica. O software, desenvolvido pelo Grupo de Pesquisa em Recursos Hídricos da Universidade Federal de Viçosa (UFV), facilita análises hidrológicas de séries históricas de vazão, com diferentes distribuições de probabilidade e estimativa de vazões mínimas, médias e máximas (Sousa 
et al., 2009). Devido sua eficiência, o SisCAH tem sido utilizado por estudantes e técnicos da área de gestão de recursos hídricos.

O pré-processamento considerou o início do ano hidrológico em outubro, e descarte de meses com percentual de falhas igual ou superior a 5\%. Cinco distribuições estatísticas foram avaliadas para verificar a com melhor ajuste, sendo elas: Weibull, Pearson III, Log-Pearson III, Log-Normal II e Log-Normal III. A distribuição estatística que melhor se ajustou nas quatro estações foi Log-Pearson Tipo III.

Posteriormente, calculou a $Q_{7,10}$ segundo metodologia de Souza (1993) - Deflúvios Superficiais no Estado de Minas Gerais. Para produzir o efeito de comparação, os cálculos considerando esta metodologia abordou as bacias à montante dos pontos onde estão localizadas as quatro estações fluviométricas analisadas anteriormente.

O método consiste em caracterizar a "Tipologia Regional Homogênea" onde está localizada a estação ou ponto analisado, obtendo então os dados necessários para o cálculo. A base de dados georreferenciada contendo as isolinhas de regionalização foi obtida através de download na plataforma IDE-SISEMA, possibilitando então o conhecimento dos dados necessários em cada um dos pontos onde se localizam as estações anteriormente analisadas.

A vazão mínima de duração mensal e recorrência decendial $\left(\mathrm{Q}_{10, \mathrm{M}}\right)$ foi calculada por meio da seguinte equação:

onde:

$$
Q_{10, M}=R e_{10, M} \cdot A d
$$

$\operatorname{Re}_{10, \mathrm{M}}$ : Rendimento Específico Médio Mensal - Mínimas com 10 anos de Recorrência;

Ad: Área de drenagem à montante da estação.

O Fator de Proporção $\left(\mathrm{F}_{\mathrm{T}, \mathrm{D}}\right)$ fornecido pela função de inferência para rendimentos mínimos foi determinado pela Equação 2.

$$
F_{T, D}=\left(\alpha+\beta+\gamma^{D}\right) \cdot(\log T)^{-(r \cdot \log T+S) \cdot D^{\left(m+n \cdot \log ^{2} r\right)}}
$$

Considerou-se um evento com período de retorno (T) de 10 anos e duração (D) de 7 dias. Os valores paramétricos tabelados para a função de inferência foram obtidos no Anexo 3, do livro Deflúvios Superficiais no Estado de Minas Gerais (Souza, 1993).

Por fim, os resultados obtidos permitiram o cálculo da $\mathrm{Q}_{7,10}$ através da equação a seguir:

$$
Q_{7,10}=F_{7,10} \cdot Q_{10, M}
$$

Em seguida, foi obtida a $\mathrm{Q}_{7,10}$ segundo metodologia de Igam (2012) - Estudo de Regionalização de Vazão para o Aprimoramento do Processo de Outorga no Estado de Minas Gerais. Para isso, foi realizada consulta na plataforma IDESISEMA, habilitando a camada do citado estudo e clicando sobre a hidrografia nos pontos onde se localizam as estações fluviométricas, automaticamente obtendo os valores.

Os resultados foram tabelados e utilizou-se a Equação 4 para obter a disponibilidade hídrica das bacias estudadas, considerando a $\mathrm{Q}_{7,10}$ obtida com cada um dos três métodos utilizados.

onde:

$$
D H B=50 \% \cdot Q_{7_{110}}-Q_{\text {dem }}
$$

DHB = Disponibilidade Hídrica da Bacia (superficial);

$\mathrm{Q}_{\mathrm{dem}}=$ Vazão demandada, ou seja, soma das vazões totais de usos outorgados. 
Por fim, os resultados obtidos por meio das três metodologias utilizadas no estudo foram comparados, avaliando as variações entre as mesmas, assim como, a disponibilidade hídrica superficial da bacia hidrográfica estudada.

\section{Resultados e Discussão}

Na data de 28 de setembro de 2020, data de coleta dos dados, existiam 118 pontos de outorga de uso da água, com captações superficiais regularizadas e válidas na circunscrição hidrográfica do rio Suaçuí, com demanda de 4,45 m³/s.

Dada a vocação agropecuarista, o tipo de uso consuntivo da água predominante na bacia do rio Suaçuí é a irrigação, correspondendo a $44 \%$ da vazão consumida, seguido de abastecimento público, que soma 29\%, devido a densidade populacional da bacia. O terceiro maior uso é aspersão em vias, que corresponde a $14 \%$ das retiradas. Os demais usos como consumo agroindustrial, dessedentação animal e extração mineral, são pouco expressivos na bacia, sendo que cada um corresponde a aproximadamente $1 \%$ das retiradas.

Para a comparação das metodologias em estudo, primeiramente, calculou-se a $\mathrm{Q}_{7,10}$ considerando as séries históricas das estações fluviométricas disponíveis. Após obtenção das respectivas séries históricas e processamento no software SISCAH 1.0, foram obtidos os seguintes resultados (Quadro 2).

Quadro 2 - $\mathrm{Q}_{7,10}$ considerando as séries históricas das estações fluviométricas disponíveis.

\begin{tabular}{|c|c|c|c|c|}
\hline $\begin{array}{c}\text { Estação } \\
\text { Fluviométrica }\end{array}$ & $\begin{array}{c}\text { Vila Matias } \\
\text { Montante }\end{array}$ & $\begin{array}{c}\text { São Pedro do } \\
\text { Suaçuí }\end{array}$ & $\begin{array}{c}\text { Fazenda } \\
\text { Corrente }\end{array}$ & Campanário \\
\hline $\mathbf{Q}_{\mathbf{7}, \mathbf{1 0}}\left(\mathbf{m}^{\mathbf{3}} \mathbf{s}\right)$ & 10,92 & 6,82 & 2,22 & 0,174 \\
\hline
\end{tabular}

Fonte: Autores (2021).

Para o cálculo da $\mathrm{Q}_{7,10}$ considerando a metodologia dos “Deflúvios Superficiais no Estado de Minas Gerais”, de Souza (1993), verificou-se na literatura que as quatro estações fluviométricas analisadas se encontram na Tipologia Regional Homogênea 211, conforme demonstra a Figura 3. 
Research, Society and Development, v. 11, n. 3, e0211325987, 2022

(CC BY 4.0) | ISSN 2525-3409 | DOI: http://dx.doi.org/10.33448/rsd-v11i3.25987

Figura 3 - Mapa “Tipologias Regionais Homogêneas”, segundo Souza (1993).

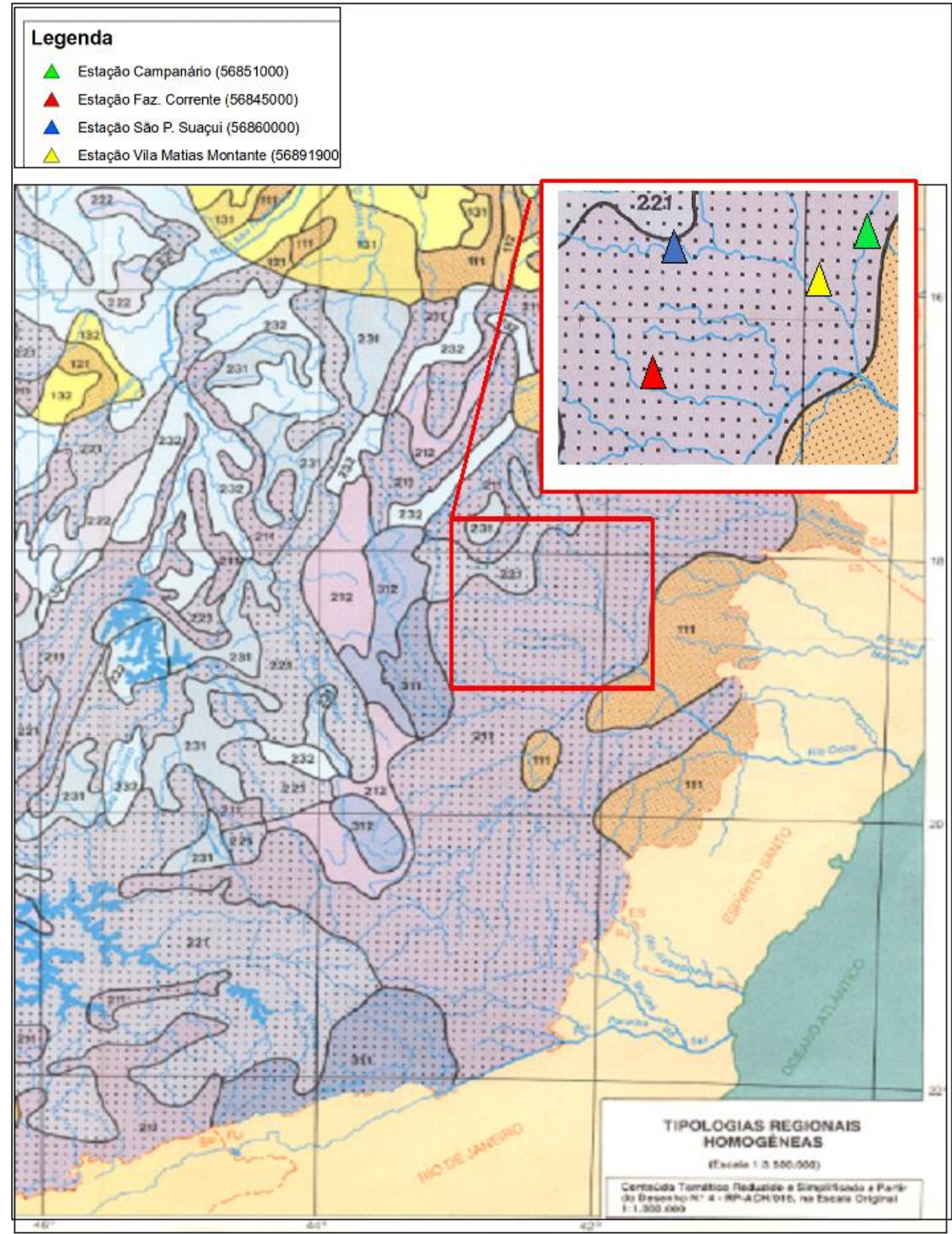

Fonte: Adaptado de Souza (1993).

A partir da definição da Tipologia Regional Homogênea foi possível obter os valores paramétricos tabelados para a função de inferência para rendimentos mínimos a partir do Anexo 3 do livro "Deflúvios Superficiais no Estado de Minas Gerais" de Souza (1993), conforme a Figura 4. 
Research, Society and Development, v. 11, n. 3, e0211325987, 2022

(CC BY 4.0) | ISSN 2525-3409 | DOI: http://dx.doi.org/10.33448/rsd-v11i3.25987

Figura 4 - Valores paramétricos para função de inferência para rendimentos mínimos.

\begin{tabular}{|c|c|c|c|c|c|c|c|}
\hline \multirow{3}{*}{$\begin{array}{l}\text { TIPOLOCIA } \\
\text { HOMOCSNER } \\
\text { (CÓD too) }\end{array}$} & \multicolumn{6}{|c|}{ 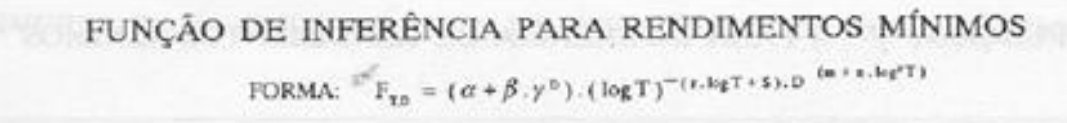 } & \multirow[b]{3}{*}{ n } \\
\hline & \multicolumn{6}{|c|}{ parkfuerros } & \\
\hline & $a$ & $\beta$ & $y$ & $y$ & . & $\mathrm{n}$ & \\
\hline 111 & 0,482396 & 0,415234 & 1,005878 & 0,218569 & 0,217688 & $-0,015536$ & $-0,041697$ \\
\hline 112 & 0,480076 & 0,402981 & 1,007266 & 0,246250 & 0,336822 & 0,000563 & $-0,034266$ \\
\hline 121 & 0.489924 & 0,398269 & 1,006209 & 0,227272 & 0,199395 & $-0,006555$ & $-0,038427$ \\
\hline 122 & 0,475558 & 0,399228 & 1.007556 & 0,275545 & 0,359782 & $-0,004670$ & $-0,038005$ \\
\hline 132 & 0,477122 & 0,393082 & 1,008173 & 0,273253 & 0.374222 & 0,017035 & $-0,026872$ \\
\hline 132 & 0,475088 & 0,403761 & 1,007164 & 0,240521 & 0,337239 & 0,003595 & $-0,0.35498$ \\
\hline 211 & 0,465547 & 0,402822 & 1,007099 & 0,175113 & 0,212533 & $-0,008058$ & $-0,032602$ \\
\hline
\end{tabular}

Fonte: Souza (1993).

No software ArcGis, a partir da localização da estação fluviométrica em relação às isolinhas da base da dados de regionalização do método desenvolvido por Souza (1993), foi obtido o valor do Rendimento Específico Médio Mensal Mínimas com 10 anos de recorrência $\left(\operatorname{Re}_{10,}\right)$, para cada um dos pontos onde se localizam as estações, conforme ilustra a Figura 5 .

Figura 5 - Mapa da CH DO4 contendo as isolinhas de rendimento específico médio mensal - mínimas com 10 anos de recorrência $\left(\operatorname{Re}_{10, \mathrm{M}}\right)$ e a localização das estações fluviométricas.

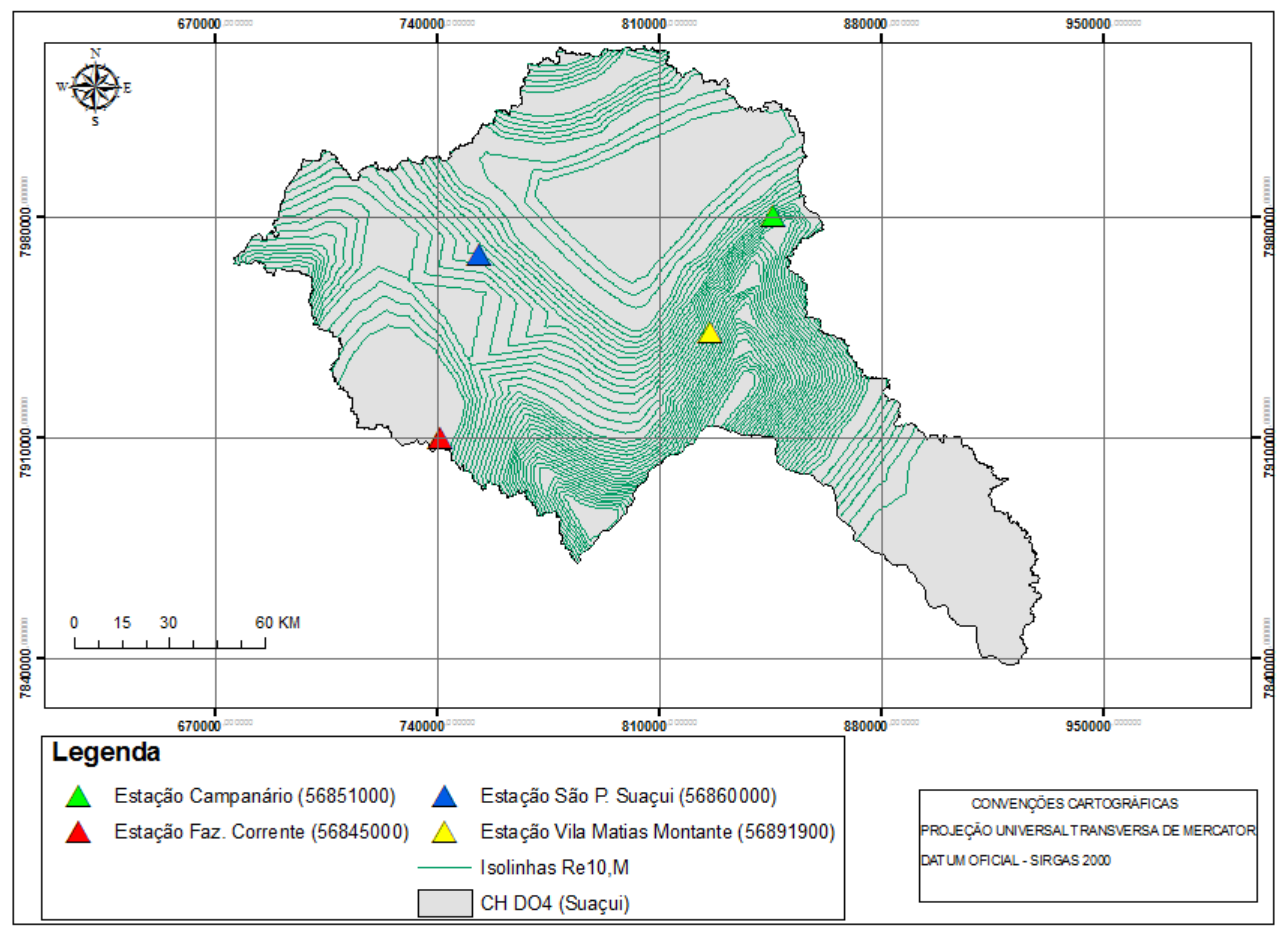

Fonte: Autores (2021).

Os valores de $\mathrm{Re}_{10, \mathrm{M}} \mathrm{e}$ áreas de drenagem à montante das estações fluviométricas, a partir das informações anteriores, estão demonstrados no Quadro 3. 
Quadro 3 - Valores de $\operatorname{Re}_{10, \mathrm{M}}$ encontrados para cada estação fluviométrica.

\begin{tabular}{|c|c|c|c|c|}
\hline Parâmetros & Campanário & Vila Matias Montante & São Pedro do Suaçuí & Fazenda Corrente \\
\hline $\operatorname{Re}_{10, \mathbf{M}}(\mathbf{L} / \mathbf{s . k m})^{2}$ & 3,4 & 5,0 & 3,4 & 3,2 \\
\hline Área de drenagem $\left(\mathbf{k m}^{2}\right)$ & 758 & 9.770 & 2.570 & 1.050 \\
\hline
\end{tabular}

Fonte: Autores (2021).

Assim, substituindo os valores e parâmetros nas respectivas equações, tem-se os seguintes resultados para $\mathrm{Q}_{7,10}$, apresentados no Quadro 4.

Quadro 4 - Valores de $\mathrm{Q}_{7,10}$ obtidos segundo metodologia de Souza (1993).

\begin{tabular}{|c|c|c|c|c|}
\hline & Campanário & $\begin{array}{l}\text { Vila Matias } \\
\text { Montante }\end{array}$ & $\begin{array}{c}\text { São Pedro do } \\
\text { Suaçuí }\end{array}$ & $\begin{array}{l}\text { Fazenda } \\
\text { Corrente }\end{array}$ \\
\hline $\mathrm{Q}_{10, \mathrm{M}}=\operatorname{Re}_{10, \mathrm{M}} \cdot \mathrm{Ad}$ & $2.577,2$ & $48.850,0$ & $8.738,0$ & $3.360,0$ \\
\hline 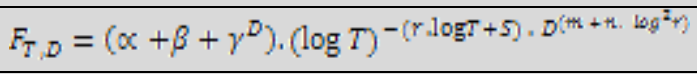 & 0,88 & 0,88 & 0,88 & 0,88 \\
\hline $\mathrm{Q}_{7,10}=F_{7,10} \times \mathrm{Q}_{10, \mathrm{M}}(\mathrm{L} / \mathrm{s})$ & $2.267,9$ & $42.988,0$ & $7.689,4$ & $2.956,8$ \\
\hline $\mathrm{Q}_{7,10}\left(\mathrm{~m}^{3 / \mathrm{s}}\right)$ & 2,27 & 42,99 & 7,69 & 2,96 \\
\hline
\end{tabular}

Fonte: Autores (2021).

Por fim, fez-se o cálculo da $\mathrm{Q}_{7,10}$ considerando a metodologia do "Estudo de Regionalização de Vazão para o Aprimoramento do Processo de Outorga no Estado de Minas Gerais”, do Igam (2012). Os valores de $\mathrm{Q}_{7,10}$ foram obtidos por meio de simples consulta na plataforma IDE-SISEMA, e estão apresentados no Quadro 5.

Quadro 5 - Valores de $\mathrm{Q}_{7,10}$ obtidos no IDE-SISEMA (Igam, 2012).

\begin{tabular}{|c|c|c|c|c|}
\hline & Campanário & Vila Matias Montante & São Pedro do Suaçuí & Fazenda Corrente \\
\hline $\mathbf{Q}_{7,10}\left(\mathbf{m}^{\mathbf{3}} / \mathbf{s}\right)($ Igam, 2012) & 0,95 & 30,53 & 5,46 & 1,89 \\
\hline
\end{tabular}

Fonte: Autores (2021).

No Quadro 6 são apresentados os resultados obtidos a partir da utilização das três metodologias citadas, para os pontos onde se localizam cada uma das estações fluviométricas.

Quadro 6 - Comparativo entre os valores de $\mathrm{Q}_{7,10}$ para cada estação fluviométrica, a partir dos métodos utilizados.

\begin{tabular}{|c|c|c|c|c|}
\hline & Campanário & $\begin{array}{c}\text { Vila Matias } \\
\text { Montante }\end{array}$ & $\begin{array}{c}\text { São Pedro do } \\
\text { Suaçuí }\end{array}$ & $\begin{array}{c}\text { Fazenda } \\
\text { Corrente }\end{array}$ \\
\hline $\mathbf{Q}_{7, \mathbf{1 0}}\left(\mathbf{m}^{\mathbf{3} / \mathbf{s}}\right)$ (Séries Históricas) & 0,174 & 10,92 & 6,82 & 2,22 \\
\hline $\mathbf{Q}_{7,10}\left(\mathbf{m}^{\mathbf{3}} / \mathbf{s}\right)$ (Souza, 1993) & 2,27 & 42,99 & 7,69 & 2,96 \\
\hline $\mathbf{Q}_{7,10}\left(\mathbf{m}^{3} / \mathbf{s}\right)$ (Igam, 2012) & 0,95 & 30,53 & 5,46 & 1,89 \\
\hline
\end{tabular}

Fonte: Autores (2021).

Verifica-se que, em ambas os métodos, a maior e a menor vazões de referência ocorreram, respectivamente, nas bacias hidrográficas com maior (Vila Matias; $9770 \mathrm{~km}^{2}$ ) e menor (Campanário; $758 \mathrm{~km}^{2}$ ) área de drenagem. Pela análise estatística das séries históricas, as vazões estimadas variaram entre 0,174 e 10,92 m³/s. 
Nota-se que a metodologia de Souza (1993) - "Deflúvios Superficiais no Estado de Minas Gerais" - em ambas as estações fluviométricas apresentou os maiores valores da vazão $Q_{7,10}$, ou seja, superestimou a vazão quando comparada a análise dos dados observados na série histórica. A maior disparidade, em relação as outras metodologias, ocorreu na estação de Campanário.

Observa-se grande variação entre os resultados encontrados, o que vai ao encontro do trabalho realizado por Sugai et al. (1998), que também constatou diferenças expressivas, comparando o método de regionalização hidrológica e a análise dos dados existentes.

Moreira et al. (2010) afirma que diferentes metodologias de regionalização de vazão possuem potencial para a verificação da disponibilidade hídrica, no entanto, deve-se estudar minuciosamente a aplicação dos métodos de acordo com as características da bacia hidrográfica, para evitar problemas no gerenciamento dos recursos hídricos.

Quando comparados os dois métodos de regionalização de vazões utilizados, em relação à análise dos dados das estações fluviométricas, foram constatadas variações de $-19,94 \%$ a 1.304,6\%, conforme demonstra o quadro a seguir.

Quadro 7 - Diferenças entre os métodos de regionalização de vazões utilizados, em relação à análise estatística das séries históricas de cada estação fluviométrica.

\begin{tabular}{|c|c|c|c|}
\cline { 2 - 4 } \multicolumn{1}{c|}{} & $\begin{array}{c}\text { Estações e } \mathbf{Q}_{7,10}\left(\mathbf{m}^{\mathbf{3}} / \mathbf{s}\right) \\
\text { (séries históricas) }\end{array}$ & $\begin{array}{c}\mathbf{Q}_{7,10}\left(\mathbf{m}^{\mathbf{3}} / \mathbf{s}\right) \\
(\mathbf{S o u z a}, \mathbf{1 9 9 3})\end{array}$ & $\begin{array}{c}\mathbf{Q}_{7,10}\left(\mathbf{m}^{\mathbf{3}} / \mathbf{s}\right) \\
(\mathbf{I g a m}, \mathbf{2 0 1 2})\end{array}$ \\
\hline \multirow{3}{*}{ Diferença (\%) } & Campanário (0,174) & $2,27(1.304,6 \%)$ & $0,95(545,97 \%)$ \\
\cline { 2 - 4 } & Vila Matias Montante (10,92) & $42,99(393,68 \%)$ & $30,53(279,57 \%)$ \\
\cline { 2 - 4 } & São Pedro do Suaçuí (6,82) & $7,69(12,75 \%)$ & $5,46(-19,94 \%)$ \\
\cline { 2 - 4 } & Faz. Corrente (2,22) & $2,96(33,33 \%)$ & $1,89(-14,86 \%)$ \\
\hline
\end{tabular}

Fonte: Autores (2021).

Observa-se que a maior variação entre as vazões estimadas pela análise estatística das séries históricas e os métodos de regionalização ocorreu na estação com menor área de drenagem (estação de Campanário). Esse fato também foi observado no estudo de Moreira e Silva (2014), em que os autores analisaram diferentes métodos para a estimativa de vazão da bacia do rio Paraopeba. Segundo os autores, tal comportamento pode se justificar devido a maior proximidade das regiões de cabeceira.

As diferenças entre os métodos para definição de vazão de referência com sub ou superestimativa das vazões outorgáveis na área de estudo podem ocasionar graves problemas na gestão efetiva dos recursos hídricos e nos valores passíveis de outorga. Além disso, a subestimativa de vazões pode inviabilizar a instalação de empreendimentos e, consequentemente, impactar o desenvolvimento econômico regional (Santana, Barros \& Silva, 2005). Por outro lado, a superestimativa das vazões pode gerar conflitos pelo uso das águas.

Apesar da grande diferença entre os resultados, a análise da disponibilidade hídrica foi realizada considerando a $\mathbf{Q}_{7,10}$ obtida pelas três metodologias, considerando aspectos de segurança, obtendo também três resultados distintos. Os resultados são apresentados no Quadro 8. 
Quadro 8 - Disponibilidade hídrica superficial da bacia hidrográfica, de acordo com os três métodos estudados.

\begin{tabular}{|c|c|c|c|c|c|}
\hline Bacia Hidrográfica & $\mathbf{Q}_{\mathrm{dem}}\left(\mathbf{m}^{3} / \mathbf{s}\right)$ & Método & $\begin{array}{c}\mathbf{Q}_{7,10} \\
\left(\mathbf{m}^{3} / \mathbf{s}\right)\end{array}$ & $\begin{array}{c}\mathbf{5 0 \%} \mathbf{Q}_{7,10} \\
\left(\mathbf{m}^{3} / \mathbf{s}\right)\end{array}$ & DHB $\left(\mathbf{m}^{3} / \mathbf{s}\right)$ \\
\hline \multirow{3}{*}{ Vila Matias Montante } & \multirow{3}{*}{1,05} & Séries históricas & 10,92 & 5,46 & 4,41 \\
\hline & & Souza, 1993 & 42,99 & 21,50 & 20,45 \\
\hline & & Igam, 2012 & 30,53 & 15,27 & 14,22 \\
\hline \multirow{3}{*}{ São Pedro do Suaçuí } & \multirow{3}{*}{0,08} & Séries históricas & 6,82 & 3,41 & 3,06 \\
\hline & & Souza, 1993 & 7,69 & 3,85 & 3,77 \\
\hline & & Igam, 2012 & 5,46 & 2,73 & 2,65 \\
\hline \multirow{3}{*}{ Fazenda Corrente } & \multirow{3}{*}{0,82} & Séries históricas & 2,22 & 1,11 & 0,29 \\
\hline & & Souza, 1993 & 2,96 & 1,48 & 0,66 \\
\hline & & Igam, 2012 & 1,89 & 0,95 & 0,13 \\
\hline \multirow{3}{*}{ Campanário } & \multirow{3}{*}{0,01} & Séries históricas & 0,17 & 0,09 & 0,08 \\
\hline & & Souza, 1993 & 2,27 & 1,14 & 1,13 \\
\hline & & Igam, 2012 & 0,95 & 0,48 & 0,47 \\
\hline
\end{tabular}

Fonte: Autores (2021).

A bacia hidrográfica à montante da estação fluviométrica Vila Matias Montante possui maior demanda de vazão outorgada $\left(1,05 \mathrm{~m}^{3} / \mathrm{s}\right)$, seguida pela bacia da estação Fazenda Corrente $\left(0,82 \mathrm{~m}^{3} / \mathrm{s}\right)$. A menor demanda ocorre na bacia hidrográfica da estação de Campanário.

Considerou-se a disponibilidade hídrica máxima passível de outorga, segundo a legislação de Minas Gerais, que corresponde a $50 \%$ da $\mathrm{Q}_{7,10}$. Observa-se que, nas três metodologias, a bacia hidrográfica à montante da estação Fazenda Corrente apresenta maior demanda por disponibilidade, o que demonstra certo comprometimento da disponibilidade hídrica.

Nos últimos anos, em porções da bacia hidrográfica do rio Suaçuí houve declaração de escassez hídrica pelo órgão ambiental gestor - Igam, além da verificação de tendência de redução das vazões médias. Nesse sentido, destaca-se que o estudo da disponibilidade hídrica colabora na gestão dos recursos hídricos, para a minimização de possíveis conflitos na área estudada.

\section{Conclusão}

Neste estudo foram utilizadas três metodologias de definição de vazão de referência para a bacia hidrográfica do rio Suaçuí (CH DO4), para verificação da disponibilidade hídrica superficial, além de comparar os resultados e a metodologia utilizada atualmente no estado de Minas Gerais.

Verificou-se consideráveis variações entre os métodos utilizados (-19,94\% a 1.304,6\% comparando os dois métodos de regionalização de vazões utilizados, em relação à análise dos dados das estações fluviométricas). Mesmo com a variação, pode-se afirmar que o balanço entre oferta e demanda hídrica é positivo.

As análises realizadas nas bacias à montante das estações fluviométricas estudadas revelaram que as vazões captadas nas respectivas bacias não produzem impactos capazes de comprometer a disponibilidade hídrica, considerando a disponibilidade total à montante das mesmas, exceto para a bacia à montante da estação "Fazenda Corrente", cuja relação “demanda/disponibilidade" foi maior que $60 \%$, em todos os métodos de cálculo, indicando certo grau de comprometimento da disponibilidade hídrica.

Portanto, este estudo evidencia a necessidade de investimentos nos sistemas de obtenção de dados fluviométricos, de forma a ampliar a cobertura de estações fluviométricas na rede hidrográfica da bacia do rio Suaçuí, bem como nas demais bacias brasileiras, haja vista as discrepâncias entre os resultados encontrados entre os métodos de regionalização de vazões. 
Recomenda-se pesquisas futuras que comparem outros métodos de regionalização de vazões, buscando resultados com menores variações estatísticas em relação às estações fluviométricas observadas, ou até mesmo o desenvolvimento de métodos específicos à bacia do rio Suaçuí, no sentido de contribuir para o processo de tomada de decisão no gerenciamento dos recursos hídricos.

\section{Referências}

ANA - Agência Nacional de Águas e Saneamento Básico. (2017). Conjuntura dos recursos hídricos no Brasil: relatório pleno. ANA.

Borsoi, Z. M. F \& Torres, S. D. A. (1997). A política de recursos hídricos no Brasil. Revista do BNDES, 4 (8), 143-166. https://web.bndes.gov.br/bib/jspui/handle/1408/11774.

Brasil. (1997). Lei Federal $n^{\circ}$ 9.433, de 8 de janeiro de 1997. Institui a Política Nacional de Recursos Hídricos, cria o Sistema Nacional de Gerenciamento de Recursos Hídricos, regulamenta o inciso XIX do art. 21 da Constituição Federal, e altera o art. $1^{\circ}$ da Lei ${ }^{\circ} 8.001$.

Consórcio Ecoplan - Lume. (2010). Plano de Ação de Recursos Hídricos da Unidade de Planejamento e Gestão dos Recursos Hídricos Suaçuí. https://www.cbhdoce.org.br//wp-content/uploads/2016/12/PARH_Suacui.pdf.

Euclydes, H. P., Ferreira, P. A., Rubert, O. A. \& Santos, R. M. (2001) Regionalização Hidrológica na Bacia do Alto São Francisco a montante da barragem de Três Marias, Minas Gerais. Revista Brasileira de Recursos Hídricos, 6 (2), 81-105. 10.21168/rbrh.v6n2.p81-105.

Faria, L.V, Brito, G. C. B., Cagna, C. E. \& Leão, G. O. (2016). Metodologia do Zoneamento Ambiental Produtivo - ZAP de sub-bacias hidrográfica. Ed 2a, Belo Horizonte: SEMAD/ SEAPA.

Garbossa, L. H. P. \& Pinheiro, A. (2015). Vazões de referência para gestão de bacias hidrográficas rurais e urbanas sem monitoramento. Revista de Gestão de Águas da América Latina, 12 (1), 43-52. 10.21168/rega.v12n1.p43-52.

Harris, N. M., Gurnell, A. M., Hannah, D. M. \& Petts, G. E. (2000). Classification of river regimes: a context for hydroecology. Hydrological Processes, 14, 2831-2848. 10.1002/1099-1085(200011/12)14:16/17<2831::AID-HYP122>3.0.CO;2-O.

Hrachowitz, M., Savenije, H. H. G., Blöschl, G., Mcdonnell, J. J., Sivapalan, M., Pomeroy, J. W., Arheimer, B., Blume, T., Clark, M. P., Ehret, U., Fenicia, F., Freer, J. E., Gelfan, A., Gupta, H. V., Hughes, D. A., Hut, R. W., Montanari, A., Pande, S., Tetzlaff, D., Troch, P. A., Uhlenbrook, S., Wagener, T., Winsemius, H. C., Woods, R. A., Zehe, E. \& Cudennec, C. (2013). A decade of Predictions in Ungauged Basins - a review. Hydrological Sciences Journal, 58 (6), 1198-1255. 10.1080/02626667.2013.803183.

Igam - Instituto Mineiro de Gestão das Águas. (2010). Manual Técnico e Administrativo de Outorga de Direito de Uso de Recursos Hídricos no Estado de Minas Gerais. http://www.repositorioigam.meioambiente.mg.gov.br/bitstream/123456789/864/3/Manual\%20tecnico\%20administrativo_MINAS\%20G ERAIS_2010.pdf

Igam - Instituto Mineiro de Gestão das Águas. (2012). Estudo de Regionalização de Vazão para o Aprimoramento do Processo de Outorga no Estado de Minas Gerais. Belo Horizonte: Igam.

Maia, J. L., Mauad, F. F. \& Barbosa, A. A. (2005). Estabelecimento de vazões de outorga na bacia hidrográfica do alto Sapucaí, com a utilização de sazonalidade. In Anais do 16 Simpósio Brasileiro de Recursos Hídricos, João Pessoa.

Matias, F. J. N. (2018). Regionalização de vazões na bacia hidrográfica do Baixo Rio Grande_UPGRH-GD8. 2018. 105 p. Dissertação de Mestrado, Universidade Federal de Uberlândia, Uberlândia, MG.

Medeiros, M. J. (2000). Avaliação da vazão referencial como critério de outorga dos direitos de usos das águas na bacia do Paraopeba. 2000.176 p. Dissertação de Mestrado, Universidade Federal de Minas Gerais, Belo Horizonte, MG.

Moreira, M. C. \& Silva, D. D. (2014). Análise de métodos para estimativa das vazões da Bacia do Rio Paraopeba. Revista Brasileira de Recursos Hídricos, 19(2), 313-324. 10.21168/rbrh.v19n2.p313-324.

Moreira, M. C., Pruski, F. F., Silva, D. D., \& Silva, J. M. A. (2010). Comparação dos valores da Q vazões. Revista Engenharia na Agricultura, 18(6), 522-528. 10.13083/reveng.v18i6.204.

Obregon, E., Tucci, C. E. M. \& Goldenfum, J. A. (1999). Regionalização de vazões com base em séries estendidas: bacias afluentes à lagoa Mirim, RS. Revista Brasileira de Recursos Hídricos, 4 (1), 57-75. 10.21168/rbrh.v4n1.p57-75.

Parajka, J., Merz, R. \& Blöschl, G. (2005). A comparison of regionalisation methods for catchment model parameters. Hydrology and Earth System Sciences Discussions, 2, 509-542. 10.5194/hess-9-157-2005.

Pereira A. S., Shitsuka, D. M., Pereira, F. J. \& Shitsuka, R. (2018). Metodologia da pesquisa científica. https://repositorio.ufsm.br/bitstream/handle/1/15824/Lic_Computacao_Metodologia-Pesquisa-Cientifica.pdf?sequence=1 .

Pereira, E. M. (2012). Análise de conflitos pelo uso da água relacionados à oferta e à demanda: Bacia do Rio Piracicaba - MG. Dissertação de Mestrado, Universidade Federal de Minas Gerais, Belo Horizonte, MG.

Ribeiro, M. M. R. (2000). Alternativas para a outorga e a cobrança pelo uso da água: simulação de um caso. Tese de Doutorado, Universidade Federal do Rio Grande do Sul, Porto Alegre, RS. 
Research, Society and Development, v. 11, n. 3, e0211325987, 2022

(CC BY 4.0) | ISSN 2525-3409 | DOI: http://dx.doi.org/10.33448/rsd-v11i3.25987

Santana, A. G., Barros, L. M. \& Silva, F. F. (2005). Avaliação de métodos para determinação da disponibilidade hídrica para fins de outorga no Triângulo Mineiro - Iturama: Estudo de caso do ribeirão Tronqueira. In: Anais Simpósio Brasileiro de Recursos Hídricos. João Pessoa.

SEMAD - Secretaria de Estado de Meio Ambiente e Desenvolvimento Sustentável. (2019). Fiscalização Ambiental 2019 - Relatório de Atividades.

Silva, L. M. C. \& Monteiro, R. A. (2004). Outorga de direito de uso de recursos hídricos: uma das possíveis abordagens. Interciência, 1, 140-179.

Soares, P. A., Pinheiro, A., Soares, H. L. \& Zucco, E. (2010). Estimativa da disponibilidade hídrica em pequenas bacias hidrográficas com escassez de dados fluviométricos. Revista de Estudos Ambientais, 12 (1), 29-38. 10.7867/1983-1501.2010v12n1p29-38.

Sousa, H. T. (2009). Sistema computacional para regionalização de vazões. Dissertação de Mestrado, Universidade Federal de Viçosa, Viçosa, MG.

Souza, J. F. (2011). Sistema de informações para apoio ao planejamento e gestão de recursos hídricos. Dissertação de Mestrado, Universidade Federal de Viçosa, Viçosa, MG.

Souza, S. M. T. (1993). Deflúvios superficiais no Estado de Minas Gerais. Hidrossistemas.

Stinghen, C. M. \& Mannich, M. (2019). Diagnóstico de outorgas de captação e lançamento de efluentes no Paraná e impactos dos usos insignificantes. Revista de Gestão de Água da América Latina, 16 (10). 10.21168/rega.v16e10.

Sugai, M. R. V. B., Fill, H. D. \& Gomes, J. A. (1998). A importância do monitoramento na gestão de recursos hídricos. In Anais do Simpósio Internacional sobre Gestão de Recursos Hídricos.

Tucci, C. E. M. (2000). Regionalização de vazões - Hidrologia: ciência e aplicação: UFRGS/ABRH.

Tundisi, J. G. (2003). Ciclo hidrológico e gerenciamento integrado: Ciência Cultura. 